\title{
Case Report of a de Novo Mutation of PCDH19 in Saudi Family Limited to Females
}

\author{
Rawan Alsheikh ${ }^{1}$, MD, Amal Al-Qassmi ${ }^{2}$, MD \\ ${ }^{1}$ Pediatric Neurology Associated Consultant, Neurology Section in King Saud Medical City/Riyadh, SA \\ ${ }^{2}$ Pediatric Neurology Consultant, Section Head of Neurology in King Saud Medical City/Riyadh, SA
}

*Corresponding Author: Rawan Alsheikh MD; aqasmi@ ksmc.med.sa

Received 10 November 2021;

Accepted 18 December 2021;

Published 25 December 2021

\begin{abstract}
Up to date more than 60 different mutations in PCDH19 have been identified. Most of PCDH19 gene is located in Xq22 and produces nonclustered delta protocadherin. This disorder primarily manifests in heterozygote females due to random X chromosome inactivation leading to somatic mosaicism and abnormal cellular interference between cells with and without delta-protocadherin., but we a heterozygous nucleotide mutation causing amino acid 561 to change from Pro to Ser (p.Pro561Ser). This mutation was de novo, and this alteration was not found in her parents. PCDH19-related epilepsy is a distinct childhood-onset epilepsy syndrome characterized by brief clusters of febrile and afebrile seizures with onset primarily before the age of three years, cognitive impairment, autistic traits, and behavioral abnormalities. We describe the features of a de novo mutation in 3 sibling, presented with early onset of seizure, two of them were controlled and wean off medication was at age of six year and her sister at age of 10 year.The youngest sister still partially controlled on medication, she had seizure only during febrile illness.
\end{abstract}

Keywords: Genetic; PCDH19; focal seizure; sibling; anti-epileptic medications

\section{Case report}

Here we are describing three sisters (13 year-8 year- 5-year-old girl) who suffered from repetitive seizures. The oldest sister 13year-old girl developed a febrile seizure at the age of 14 months characterized by generalized loss of tone with impaired awareness lasted for few minutes. Admitted initially as febrile status for investigation suspected post viral infection to role out CNS infection. Her examination was normal neurological exam, no focal deficit and her systemic review was within normal, no sore throat or ear infection was noted. Blood work up was within normal (blood count, Chemistry, renal function ) was all normal, apart from mild lekocytosis (white blood cell 12.4), cerebral spinal fluid (CSF) analysis and culture was negative, virology culture was negative. Patient was discharge after few days in stable condition and no anti-epileptic medication was started. Later at age of 2 year and 3 months, she started to have afebrile seizures. The seizures occurred 3-4 times per week, similar to her previous description generalized tonic clonic seizure with no focality lasting 3-5 minute followed by post ictal sleep or drowsy for few hours till she is back to her baseline. Her EEG using the international 10-20 system showed generalized spike and wave. MRI brain was normal. She was diagnosed to have G.epilepsy, started on Topiramate; however, her seizures were not responsive. The longest period of remission was just 3-4 weeks. Then levetiracetam16 was introduced, later showed improvement in-term of frequency and duration (Valproic acid was not recommended but parents refuse concern about the side effect). EEG was repeated showed normal recording. She was born at full-term with a birth weight of $3.5 \mathrm{~kg}$. She had normal early developmental milestones. She was the first child of unrelated parents. There was no family history of epilepsy or intellectual disability. The patients' family pedigree is shown in Figure 1. 


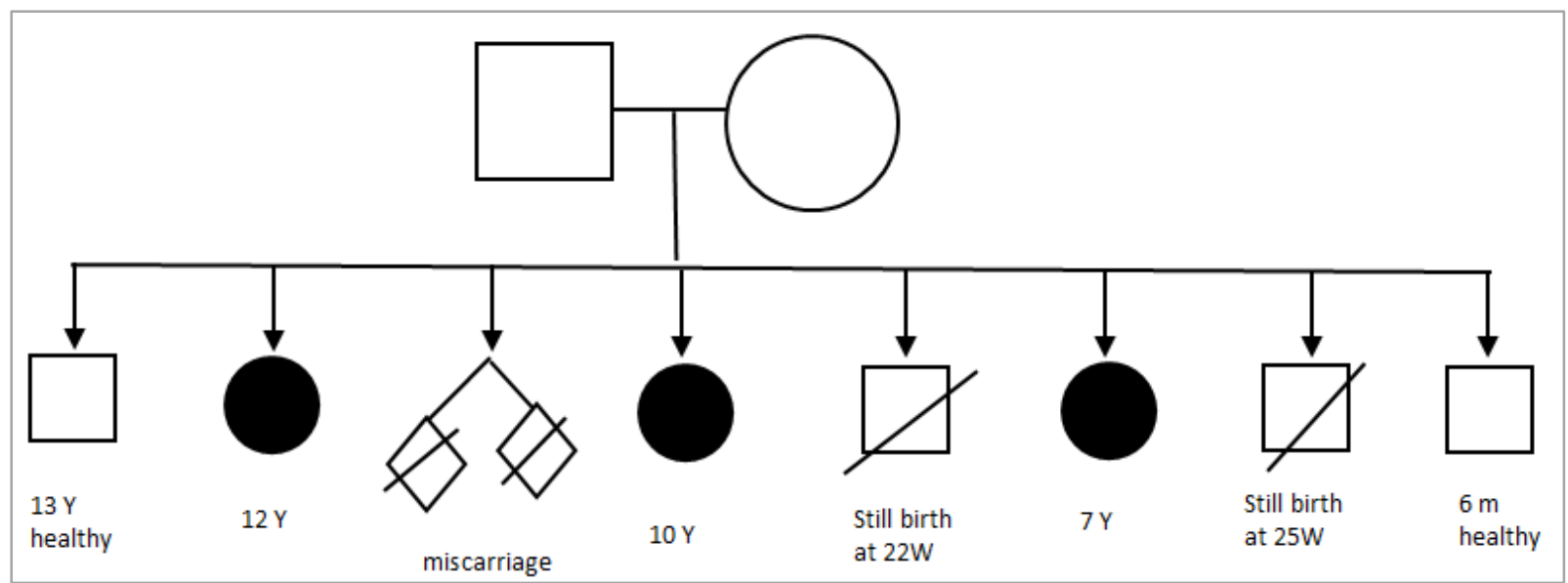

Figure 1

The second sister, an eight-year-old girl, was reported to have repetitive seizures starting at the age of 14 months. She was born at full-term without birth-related distress or dysmorphia. Perinatal history and pregnancy were both unremarkable. Her seizure started as febrile, described as a tonic seizure following by screaming and a frightened face, including loss of contact, stiff limbs, purple lips, and chewing movements. These episodes lasted for about $30 \mathrm{sec}$. Later, the seizures appeared without fever with similar semiology. EEG showed using the international 10-20 system, generalized spikes and wave higher frontal bilateral, in some epeock showed few spikes at posterior temporal at P3- T5, the last EEG showed normal recording, and an MRI brain scan is unremarkable. Levetiracetam (LEV) ${ }^{[16]}$ was started as her older sister; the patient experienced reduced attack frequency, she was on Levitrecetam for more than 2 year and at age of 5 year start to wean off medication, patient had 2 attack of generalized seizure after few months from stopping medication, Levitrecitam was continue till age of 8 year, was seizure free then start to wean off currently she is 9 year and 6 months. The onset of epilepsy seizures was accompanied by no significant developmental delay. The patient's intelligence level was not assessed by appropriate scale, whether before or after her onset. But during the follow-up period, her mother reported overall good school performance. Third sister is a 5-year-old girl. She was born at full-term via with no distress or dysmorphic features. The perinatal history and neonatal course were all unremarkable. Her first seizure displaying a right focal tonic seizure was noted during a febrile illness at the age of 9 months. The EEG done using the international 10-20 system was showing normal posterior dominant rhythm and frequent spike and wave seen at posterior head at P3$\mathrm{O} 1$ and $\mathrm{P} 4-\mathrm{O} 4$ with lesser extent to $\mathrm{T} 6$, the last reading was repeated after 8 months from initiation of medication was normal recording and no epilepti-form activity. Then the brain computed tomography (CT) done reported normal. She developed a cluster of febrile seizures by 19 months of age, lasting for approximately $10 \mathrm{~s}$ each time occurred around six times in $36 \mathrm{~h}$. By 31 months of age, a second cluster appeared triggered by fever, her seizure semiology change to sudden behavior arrest The brain MRI was also normal at this onset. Her psychomotor development was unremarkable. She received multiple antiepileptic treatments, including sodium valproate, Topiramate, phenobarbitone, and lamotrigine (started for few weeks develop skin rash, medication wean off). The longest period of remission was just two months. Her antiepileptic regimen was adjusted multiple times. Her seizure was controlled after being given carbamazepine, levetiracetam. She is seizure free for more than 1year and 5 months. Whole-exome sequencing result showed a missense mutation in the PCDH19 gene: a cytosine to guanine (C $>\mathrm{G})$ nucleotide change at position 1031 (c.1031C > G), a heterozygous nucleotide mutation causing amino acid 561 to change from Pro to Ser (p.Pro561Ser). This mutation was de novo, and this alteration was not found in her parents three mutations of PCDH19-related epilepsy were identified in three children within the same family. The clinical data and characteristics of the three patients carrying PCDH19 variations are described in Table 1 .

Table 1

\begin{tabular}{|l|l|l|l|l|l|l|l|l|}
\hline Patient & Age & Gender & $\begin{array}{l}\text { Age at } \\
\text { seizure } \\
\text { onset }\end{array}$ & $\begin{array}{l}\text { Seizure type } \\
\text { at onset }\end{array}$ & Other seizure type & EEG & Brain Image & $\begin{array}{l}\text { Development } \\
\text { before seizure } \\
\text { onset }\end{array}$ \\
\hline 1 & $5 \mathrm{y}$ & female & $9 \mathrm{M}$ & Right focal & $\begin{array}{l}\text { Generalized, focal Eye } \\
\text { gaze to the left with GTC }\end{array}$ & $\begin{array}{l}\text { Focal, posterior } \\
\text { head }\end{array}$ & unremarkable & normal \\
\hline 2 & $8 \mathrm{y}$ & Female & $14 \mathrm{M}$ & $\begin{array}{l}\text { Screaming and } \\
\text { GTC }\end{array}$ & non & GSW & unremarkable & normal \\
\hline 3 & $13 \mathrm{y}$ & Female & $14 \mathrm{M}$ & Tonic seizure & $\begin{array}{l}\text { Eye gaze to the left then } \\
\text { GTC }\end{array}$ & GSW & unremarkable & normal \\
\hline
\end{tabular}

Table 2

\begin{tabular}{|l|l|l|l|l|}
\hline Patient & Medication tried & Current medication & Seizure outcome & Current cognitive status \\
\hline 1 & $\begin{array}{l}\text { Topiramate velprate } \\
\text { phenobarbitone lamotrigin }\end{array}$ & $\begin{array}{l}\text { Carbamazepine, } \\
\text { levetiracetam }\end{array}$ & Seizing on ASMs & Normal \\
\hline 2 & levetiracetam & & One year off meds, No seizure & Normal \\
\hline 3 & Topiramate & levetiracetam & Controlled, seizure free, off medication & Difficulty in memorizing \\
\hline
\end{tabular}




\section{Discussion}

We had notic in all the 3 case, each patient had different semiology of seizure and their response of anti-seziure medication was variable in spite all of them had same gene mutation and similar early presentation (febrile seizure). But there was clear good response of medication and the outcome was also good in 2 of the sibling although the youngest she showing good response apart from the intermittent breakthrough of seizure that provoked with fever. There was no clear description was mention in the other litterateur and if there is clear variability of seizure presentation in sibling. In literature, around 292 cases were reported in different studies ${ }^{[1]}$. Approximately 150 mutations of PCDH19 have been discovered, with more than half affecting extracellular adhesive domains by missense mutations as found in our patients ${ }^{[2]}$. Here, the findings from our study are compared with those of previously reported cases ${ }^{[1]}$. In previous reports, PCDH19 cases share the following features: age at the onset before three years, seizures semiology described as earlier fearful screaming, occurred in the cluster and cognitive and behavior disturbances ${ }^{[3,4]}$. Similarly, in our three patients, the seizures onset in the first year of life for one patient and after the first year of life for the other two, with an average age of onset of 12 months (9-14 months). All patients developed generalized seizures or focal seizures evolve to secondary generalization. Seizures occurred in clusters with all subjects, and patient?? Had confirmed epileptic status. All three patients had seizures associated with fever sensitivity at the onset. Patient 3 had recurrent seizures despite being treated with multiple anti-epileptic drugs, suggesting that $\mathrm{PCDH}-19$ related seizures had variations and were difficult to control to a certain degree ${ }^{[5]}$. Interictal EEG was normal in all patients, similar to what had been described in the literature. Moreover, Fast activity over a localized brain region was also described as an interictal finding. The majority of described Ictal EEG in literature is focal onset being frontotemporal most common, though generalized seizure onset has been reported ${ }^{[1]}$. Brain MRI had no particular findings in all three patients, as reported in most previous cases. However, a minority of reported cases were found to have cortical malformation and hippocampal sclerosis ${ }^{[6]}$. Psychiatric symptoms were detected among all the patients. However, patients 1 has memorizing difficulty and patient 3 developed intellectual deterioration and behavioral disturbance. Out of previously reported cases, 213 patients of 271 patients had a psychiatric illness. Autism and ADHD are mostly reported ${ }^{[7,8]}$. Regardless of the variation in clinical manifestations of PCDH19-related epilepsy, the disease shares some common characteristics, particularly the age of onset at infancy and the seizure semiology as generalized seizures and cluster seizures ${ }^{[9]}$. The most common seizure types reported are generalized tonic seizures, tonic-clonic seizures, or focal seizures with secondary generalization appearing in clusters with or without fever. Other seizure types are rare such as myoclonic seizures, atonic seizures, and atypical absences. Cognitive develoment vary from normal to sever intellactual imapairmet. In addition, Patients may or may not demonstrate psychiatric symptoms and behavioral disturbance ${ }^{[10,11]}$. Of the three patients, three genetic alterations were the same exact location suggesting inherited from their asymptomatic father. (Carrier status??) PCDH19 mutations in most patients are sporadic and de novo, while some are of paternal inheritance. This makes it challenging to recognize the pattern of inheritance ${ }^{[12,13]}$

In one patient, treatment with levetiracetam was reported as effective. In the other patients, treatment with oral polypharmacy, clonazepam (CZP), and phenobarbital (PB) also was reported as effective $^{[14,15]}$.

\section{Conclusion}

Genetic testing play a good role in diagnosis of familial epilepsy but with minimal knowledge of medication effect in those type of mutation. In our report the choice of antiepileptic medication is limited but there was response on levitrecitam as adjunctive medication but again the efficacy of medication response and better choice need base evidence.

\section{Conflict of interest}

None

\section{Acknowledgments}

We are grateful to all the subjects of the family for their participation in this study.

\section{References}

[1] Samanta D. (2019). PCDH19- related Epilepsy Syndrome: A comprehensive Clinical Review, Pediatric Neurology.

[2] Gerosa L, Francolini M, Bassani S, Passafaro M. (2019). The Role of Protocadherin 19 (PCDH19) in Neurodevelopment and in the Pathophysiology of Early Infantile Epileptic Encephalopathy-9 (EIEE9). DevNeurobiol. 79:75-84.

[3] Trivisano M, Specchio N. (2019). The role of PCDH19 in refractory status epilepticus. Epilepsy Behav. 101:106539.

[4] Smith L, Singhal N, El Achkar CM, Truglio G, Rosen Sheidley B, Sullivan J, Poduri A. (2018). PCDH19related epilepsy is associated with a broad neurodevelopmental spectrum. Epilepsia. 59(3): 679689.

[5] Erratum in. (2018). Epilepsia. 59(6):1272.

[6] Chemaly N, Losito E, Pinard JM, Gautier A, Villeneuve $\mathrm{N}$, Arbues AS, et al. (2018). Early and long-term electroclinical features of patients with epilepsy and PCDH19 mutation. Epileptic Disord. 20:457-67.

[7] Van Harssel J, Weckhuysen S, van Kempen M, Hardies K, Verbeek N, de Kovel C, et al. (2013). Clinical and genetic aspects of PCDH19-related epilepsy syndromes and the possible role of PCDH19 mutations in males with autism spectrum disorders. Neurogenetics. 14:23-34

[8] Kolc KL, Sadleir LG, Scheffer IE, Ivancevic A, Roberts R, Pham DH, et al. (2019). A systematic review and meta- analysis of 271 PCDH19-variant individuals identifies psychiatric comorbidities, and association of seizure onset and disease severity. Mol Psychiatry. 24:241-5.

[9] Vlaskamp DRM, Bassett AS, Sullivan JE, Robblee J, Sadleir LG, Scheffer IE, Andrade DM. (2019). Schizophrenia is a lateronset feature of PCDH19 Girls Clustering Epilepsy. Epilepsia. 60(3):429-440.

[10] Duszyc K, Terczynska I, Hoffman-Zacharska D. (2015). Epilepsy and mental retardation restricted to females: Xlinked epileptic infantile encephalopathy of unusual inheritance. J Appl Genet. 56(1):49-56. 
[11] Depienne C, LeGuern E. (2012). PCDH19-related infantile epileptic encepha- lopathy: an unusual X-linked inheritance disorder. Hum Mutat. 33:627-634.

[12] Huttlin EL, Bruckner RJ, Paulo JA, et al. (2017). Architecture of the human interactome defines protein communities and disease networks. Nature. 545:505-509.

[13] Perez D, Hsieh DT, Rohena L. (2017). Somatic Mosaicism of PCDH19 in a male with early infantile epileptic encephalopathy and review of the literature. Am J Med Genet A. 173:1625

[14] Scheffer IE, Turner SJ, Dibbens LM, et al. (2008). Epilepsy and mental retardation limited to females: an under-recognized disorder. Brain. 131:918-927.

[15] Yang X, Chen J, Zheng B, Liu X, Cao Z and Wang X. (2020). PCDH19-Related Epilepsy in Early Onset of Chinese Male Patient: Case Report and Literature Review. Front. Neurol. 11:311.

[16] Higurashi N, Nakamura M, Sugai M, Ohfu M, Sakauchi M,Sugawara Y, et al. (2013). PCDH19-related femalelimited epilepsy:further details regarding early clinical features and therapeutic efficacy.Epilepsy Res. 106:191199.
[17] Lynette G Sadler. (2009). Levetiracetam efficacy in PCDH19 Girls Clustering Epilepsy, Eur J Paediatr Neurol

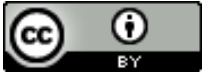

Open Access This article is licensed under a Creative Commons Attribution 4.0 International License, which permits use, sharing, adaptation, distribution and reproduction in any medium or format, as long as you give appropriate credit to the original author(s) and the source, provide a link to the Creative Commons license, and indicate if changes were made. The images or other third party material in this article are included in the article's Creative Commons license, unless indicated otherwise in a credit line to the material. If material is not included in the article's Creative Commons license and your intended use is not permitted by statutory regulation or exceeds the permitted use, you will need to obtain permission directly from the copyright holder. To view a copy of this license, visit https://creativecommons.org/licenses/by/4.0/.

(C) The Author(s) 2021 